\title{
Protecting Buyers from Fine Print
}

\author{
Elena D’Agostino* and Daniel J. Seidmann ${ }^{\dagger \ddagger}$
}

May 2016

\begin{abstract}
Buyers typically do not read the fine print in contracts, providing an incentive for a monopolist to draft terms which are unfavorable to buyers. We model this problem, proving that trade must then be inefficient. We show that regulation which mandates efficient terms raises welfare. More interestingly, regulations which prohibit the least efficient terms may reduce welfare by inducing the monopolist not to offer favorable terms. We extend these results to markets in which some buyers are naive, showing that prohibiting the least efficient terms may also harm the naive buyers.
\end{abstract}

\section{Introduction}

According to some estimates, over $99 \%$ of commercial contracts are standard form: one party drafts a contract which the other party can only accept or reject (cf. Zamir (2014)). Standard form contracts are often complex, and are written in fine print or jargon; so buyers rarely read their non-price terms. Drafters of contracts may therefore have an incentive to include terms which exploit buyers and, potentially, result in inefficient trade. Accordingly, economists and contract lawyers have long advocated regulation of the terms in complex contracts by treating some terms as unenforceable. This paper explores the effect of such policies in a model where complexity is endogenous, and unregulated trade is indeed inefficient.

In our main model, an unregulated monopolist drafts a contract (for trade in a good), which might be either simple or complex. A simple contract specifies a price for the good, which buyers observe, and default terms (such as warranty coverage) which are commonly known, perhaps because they describe conventional commercial practice. In particular, simple contracts do not contain any fine print. On the other hand, the monopolist can only change these default terms by drafting a complex contract. Specifically, a complex contract specifies a price for the good - which buyers observe - and non-price terms, which buyers can read at a (socially wasteful) cost. In other words, non-price terms are written in fine print. These terms may be more favorable or less favorable for buyers than default

\footnotetext{
*Department of Economics, University of Messina; edagostino@unime.it

†School of Economics, Nottingham University; daniel.seidmann@nottingham.ac.uk

${ }^{\ddagger}$ We are particularly grateful to an associate editor and two referees for their insightful suggestions.
} 
terms. The monopolist has the opposite incentives: it is cheaper to produce, the less favorable are terms. We assume that it is socially efficient for trade to occur in (complex) contracts which include terms which are more favorable to buyers than default terms: so complex contracts, with requisite fine print, may play a socially valuable role. Buyers observe whether the contract on offer is simple or complex (e.g. via its length). In the former case, they decide whether to accept or to reject; in the latter case, they may also choose to read before accepting or rejecting.

Trade with an unregulated monopolist must then be inefficient in every Bayes perfect equilibrium (henceforth BPE) because the monopolist cannot commit to drafting favorable terms. As a result, welfare is reduced for two reasons: buyers would only read a complex contract if the monopolist mixed over terms, sometimes offering contracts which contain unfavorable terms; and the monopolist would only offer a favorable contract if buyers sometimes read complex contracts.

This game has many BPEs because buyers may infer that any complex contract which is not offered on the path of a putative BPE contains unfavorable terms. These inferences seem unduly adverse; so we introduce a refinement which selects the BPE with the highest expected profit. This BPE takes one out of two possible forms. If reading is costly enough then the monopolist offers either a simple or an unfavorable contract; otherwise, she mixes between offering a favorable and an unfavorable contract (at the same price), while buyers mix between reading the contract and accepting without reading, earning their reservation value. These predictions are consistent with evidence that buyers rarely read (cf. Bakos et al (2014)), and that terms in complex contracts are not uniformly unfavorable (cf. Mann and Siebeneicher (2008) and Marotta-Wurgler (2008)). Furthermore, our inefficiency result provides a reason why policy makers might intervene in unregulated markets.

We consider the effects of two sorts of regulation: mandating favorable terms (henceforth mandating regulation) and prohibiting unfavorable terms (henceforth mitigating regulation). Trade under mandating regulation is efficient; and the outcome Pareto-dominates that in unregulated markets, all gains accruing to the monopolist. The intuition is that this regulation solves the monopolist's commitment problem: buyers know that complex contracts must be favorable; so the monopolist can raise price to buyers' (common) reservation value.

While mandating favorable terms would ensure efficiency, identifying efficient terms may be beyond the capacity of regulators - which is arguably why mitigating regulation is more common. Mitigating regulation prevents the monopolist drafting some inefficient terms; so it is surprising that such regulation may reduce welfare when an unregulated monopolist sometimes offers a favorable contract. The intuition is that such regulations modify rather than eliminate the monopolist's commitment problem. Consequently, the monopolist can still only offer complex contracts if buyers are prepared to read; and prohibiting unfavorable terms reduces buyers' incentives to read by lowering the utility difference between the best and worst possible terms. Mitigating regulation may therefore reduce welfare by inducing the monopolist not to offer any favorable contracts.

Following the literature, we extend our main model by introducing some naive buyers, dubbing the other buyers as sophisticated. In light of the heterogeneity of buyers, we also suppose that the monopolist can offer a menu of contracts (though she cannot tell which 
buyer is naive).

We follow the literature by supposing that naive buyers are overoptimistic: they believe that every complex contract contains favorable terms, and therefore never read. We focus on cases where few enough buyers are naive (among other conditions). If reading is cheap enough and few enough buyers are naive then an unregulated monopolist offers complex contracts at two prices. The higher priced contract is favorable with positive probability and otherwise unfavorable, and is only accepted by sophisticated buyers; the cheaper contract is always unfavorable, and is accepted by naive buyers, who wrongly believe it to be favorable. The monopolist thereby discriminates between buyers, trading an unfavorable contract with naive buyers. Naive and sophisticated buyers separate, but both trade a complex contract; so the monopolist cannot charge naive buyers more than sophisticated buyers for a complex contract. Sophisticated buyers therefore protect naive buyers, even though the monopolist offers a menu of contracts. Mandating regulation again raises welfare, and now strictly benefits naive buyers as well as the monopolist. By contrast, mitigating regulation may harm naive buyers by reducing the monopolist's incentive to offer favorable contracts to sophisticated buyers (for the same reasons as in our main model), and may therefore eliminate the protection which they provide naive buyers in unregulated markets.

Related literature

The issues which we address are related to the large literature on quality competition with sophisticated buyers. More directly, various papers incorporate a cost of reading terms which are drafted by one of the parties to the contract. ${ }^{1}$ In Katz (1990), there is an interval of feasible non-price terms, which depends on the legal regime, but no simple contract. (Simple contracts do not appear in the other papers discussed below.) A monopolist chooses a directly observable price and non-price terms which can be read at a cost, as in our model. Divisibility of all terms implies that the monopolist never mixes; she offers the most unfavorable terms that the legal regime allows, setting price such that a buyer who reads is indifferent between accepting and rejecting. This outcome is also possible in our model if unfavorable contracts yield a greater social surplus than simple contracts and reading is costly enough; but it is inconsistent with evidence that fine print terms are typically not as unfavorable as possible. If reading is not too costly then our model (with a finite number of feasible non-price terms) predicts that the monopolist would offer a favorable contract with positive probability, setting price such that buyers are indifferent between reading, accepting without reading, and rejecting. Katz shows that mandating regulation induces an efficient outcome, as in our model. However, smaller improvements in the most unfavorable possible terms raises welfare in his model, whereas mitigating regulation may reduce welfare in our model.

There is a finite number of possible terms in Rasmusen's (2001) two-player model, so the non-drafting party mixes between accepting and reading any complex contract, as in our model. Rasmusen assumes that it is costly to read every clause, so price cannot signal non-price terms. This feature plays an important role in our characterization of equilibria.

In Che and Choi (2009), competitive sellers can incur a cost to partially disclose whether terms are favorable or unfavorable; and buyers, who directly observe price, can either

\footnotetext{
${ }^{1}$ Hermalin et al's (2007) survey of the law and economics of contracts discusses these and related issues.
} 
accept or read (at a cost), and can resample sellers if they reject. In any equilibrium, as in our model, buyers who read are indifferent between accepting and reading. Furthermore, sellers separate into those offering favorable terms with high probability and not disclosing, and those who are sure to offer unfavorable terms and disclose.

There is typically a range of BPEs in Che and Choi, as in our model. Che and Choi select the BPE which maximizes welfare rather than profit. Nevertheless, the two criteria select the same BPE in our main model because our refinement implies that buyers earn their reservation value.

In contrast to Che and Choi, we do not allow the monopolist to disclose non-price terms. However, if mandatory disclosure were possible in our model then a regulated monopolist would offer a favorable contract, priced at the reservation value; and regulated trade would be efficient. This is not true in Che and Choi because they assume that sellers must offer a single contract to buyers with heterogeneous valuations.

This paper, like Katz (1990), Che and Choi (2009) and Rasmusen (2001), is related to the literature on auditing/inspection games, as surveyed by Avenhaus et al (2002) and Avenhaus and Canty (2009). Our results on unregulated trade reproduce a fundamental property of inspection games with a finite number of feasible terms: favorable contracts can only be offered in equilibrium if buyers and seller(s) monitor each other by mixing: sometimes offering unfavorable contracts and sometimes reading.

The papers hitherto surveyed assume that all buyers are sophisticated, as in our main model. A related literature, starting with Gabaix and Laibson (2006), considers competitive markets in which some buyers are naively optimistic. ${ }^{2}$ Gabaix and Laibson assume that all buyers acquire a base product from a seller after observing her price, and may either acquire an add-on or (inefficiently) incur a substitution cost. Sellers can choose any scalar price for the base product and for the add-on, and whether to offer a shrouded or an unshrouded contract. The literature focuses on this decision; we preclude such a decision by supposing that the complexity of a given contract is determined by its content (viz. whether it amends default terms).

Conditional on sellers choosing to shroud, the models share several important features, but differ in other respects. First, the opportunity to substitute away allows buyers to avoid unfavorable add-on terms, like our reading cost; though in Gabaix and Laibson, buyers can accept the base product alone, whereas buyers in our model can only avoid an unfavorable contract by rejecting. Conditional on sellers choosing to shroud, trade would be inefficient in Gabaix and Laibson for reasons akin to the inefficiency in our model and in Katz (1990): sellers would choose the most unfavorable price for the add-on, inducing sophisticated buyers to substitute away. Second, Gabaix and Laibson allow buyers to be sophisticated (in our sense) or to believe that the add-on is free (as in our model with naive buyers). Sellers compete by cutting the base product price; so exploitation of naive buyers benefits sophisticated buyers. This form of cross-subsidization is impossible in our model because the monopolist uses her menu to screen buyers in equilibrium. Indeed, sophisticated buyers protect (few enough) naive buyers in our model. This form of protection is also absent in Schwartz and Wilde's (1983) price search model, where sellers must offer the same terms to all buyers.

\footnotetext{
${ }^{2}$ This literature has recently been surveyed by Koszegi (2014) Section 6.1 and by Huck and Zhou (2011).
} 
Heidhues et al (2014) Section 4.2 builds on Gabaix and Laibson (2006) by assuming that sellers offer a menu of products (rather than of contracts), each bundling the base product and the add-on. ${ }^{3}$ Heidhues et al show that trade is efficient if enough buyers are sophisticated (contrary to our results), and that sellers use the menu to separate buyers, as in our model. In equilibrium, naive buyers are not protected because they recognize that sophisticated buyers acquire a different product; ${ }^{4}$ whereas, protection occurs in our model because naive buyers believe that the complex contracts on offer contain the same terms. Heidhues et al also show that reducing the maximal feasible price of the add-on increases welfare (as in Katz (1990)); whereas, mitigating regulation may reduce welfare in our model.

Our results are related to the literature on regulation, particularly to the study of what Armstrong and Sappington (2007) call "practical regulatory policies": the comparison of simple regulatory policies, such as price caps and disclosure. ${ }^{5}$ Imposing price caps on overdrafts in Armstrong and Vickers (2012) plays a similar role to regulations in our model. Stringent enough price caps are equivalent to mandating favorable terms in our model, and must raise welfare. Armstrong and Vickers note that the welfare effect of less stringent caps is ambiguous. However, this ambiguity turns on whether naive and sophisticated buyers cross-subsidize each other; whereas mitigating regulation could raise or lower welfare in our model when all buyers are sophisticated. Our result is also reminiscent of Armstrong et al's (2009) price search model: imposing a price cap reduces buyers' incentive to become informed (read) in competitive markets, and might therefore make all buyers worse off. More generally, our results on mitigating regulation have a second best flavor: moving regulations part way to the ideal rule may be worse than no regulation because agents' equilibrium response induces a convex relation between regulatory policy and welfare.

We present our model of unregulated monopoly in Section 2, characterizing trade in unregulated and regulated markets in Section 3. We extend our analysis to markets in which some buyers are naive in Section 4, and summarize in Section 5. Longer proofs are in an Appendix; we detail some arguments used in Section 4 in an online appendix: D'Agostino and Seidmann (2016).

\section{Unregulated trade}

In this section, we define a game representing play in an unregulated monopoly.

The game is played by a monopolist (she) and a unit mass of buyers (he). Players can trade a good which is indivisible in consumption. The monopolist offers a contract; each

\footnotetext{
${ }^{3}$ Sophisticated buyers observe both prices, unlike our model and Gabaix and Laibson (2006).

${ }^{4}$ This property holds in a number of related models in which sellers offer a menu of products: Eliaz and Spiegler (2006) [resp. (2008)] demonstrate that a monopolist's optimal menu induces time-inconsistent [resp. over-optimistic] and sophisticated buyers to separate: the former are not protected by the latter in equilibrium; Heidhues and Koszegi (2010) obtain similar results for time-inconsistent buyers and competitive sellers.

${ }^{5}$ See, for example, Armstrong et al (2009) on price caps, Korobkin (2003) on treating unfavorable terms as unconscionable, and Ayres and Schwartz (2014) on disclosure regulation. Koszegi (2014) Section 6.2 surveys this literature.
} 
buyer then decides whether to accept, to reject or to read before accepting or rejecting. The game then ends.

We now describe the game in detail:

Contracts

Contracts determine both the price at which trade takes place and some other (nonprice) terms of trade. We suppose that a contract is either simple or complex. A simple contract contains a single clause, which specifies the price charged (denoted $p$ ), but leaves non-price terms unspecified. We suppose that trade is then governed by default terms, which are commonly known by all players. Default terms might be those which courts enforce, absent amendment. They might also represent common commercial practice, which triggers reasonable expectations by buyers. ${ }^{6}$

A complex contract contains two clauses: the first clause specifies the price charged; the second clause specifies non-price terms, which might either be favorable, unfavorable or default. (Default terms repeat those implicit in a simple contract.) We will refer to complex contracts with favorable, default and unfavorable terms as favorable, default and unfavorable contracts, respectively.

Non-price terms might specify, for example, the extent of a warranty, delivery costs, the number of permissible users, the availability of class relief, or a dispute resolution procedure. In each case, all buyers share the same ranking over terms. In particular, terms are favorable [resp. unfavorable] if they are better [resp. worse] for buyers than default terms. This distinction corresponds to Marotta-Wurgler's (2008) procedure for classifying software licenses: where default terms are those specified in Article 2 of the Uniform Commercial Code, while favorable [resp. unfavorable] terms are more [resp. less] buyer-friendly. ${ }^{7}$

Our distinction between simple and complex contracts implies that the monopolist can only propose a non-default term by offering a complex contract. We view this property as a key feature of fine print models. It will play a crucial role in our analysis.

Some notation will prove useful: we write $\{p, f\},\{p, d\}$ and $\{p, u\}$ respectively for favorable, default and unfavorable contracts, each priced at $p$. We write $T$ for $\{f, d, u\}$ : the set of possible terms.

\section{Buyers}

We model the problem of complexity by supposing that buyers observe both the first clause of each contract on offer (the price) and whether it is simple or complex, but not the content of any second clause. If the contract is simple then the buyer, knowing its (default) terms, either accepts or rejects. If the contract is complex then the buyer can either accept the contract without reading, reject the offer without reading, or read the second clause and then decide whether to accept or reject.

A buyer receives a return of 0 if he does not consume, and of $b_{t}-p$ if he buys a good priced at $p$ with terms $t \in T$. We also assume that a buyer incurs a sunk cost, denoted by $k>0$, if he decides to read the second clause of a complex contract. This cost could

\footnotetext{
${ }^{6}$ According to the 2014 UK Consumer Rights Act, contract terms are only unfair if they would surprise a buyer whose expectations are reasonable.

${ }^{7}$ Similarly, Schwarcz (2011) considers whether terms in home insurance contracts are either more or less favorable than those in the Insurance Services Office's boilerplate = the default.
} 
represent the time taken to read a lengthy document or be incurred by hiring an expert to interpret jargon. A buyer's payoff is his return minus any reading cost incurred.

\section{Monopolist}

The monopolist starts the game by deciding which contract to offer, where price $p$ can take any scalar value.

If a buyer accepts a contract then the monopolist receives a revenue equal to the contractual price, and incurs a constant production cost, plus a drafting cost if her contract is complex. The drafting cost is positive, but less than $b_{f}-b_{d}$. We write $c_{f}$ [resp. $c_{u}$ ] for the total cost incurred when a favorable [rep. unfavorable] contract is accepted. It is notationally convenient to write $c_{d}$ for the (production) cost incurred when a simple contract is accepted. As default contracts are complex, trading them costs $c_{d}$ plus the drafting cost. We will subsequently argue that an unregulated monopolist never offers a default contract (because of the drafting cost). The monopolist earns 0 when a buyer does not accept. Her payoff is the integral of the profit which she earns across all buyers.

\section{Game}

We denote the game described above by $G$, and refer to it as the unregulated game. We will focus on games in which the various parameters are generic. This restriction primarily excludes cases in which $b_{d}-c_{d}=b_{u}-c_{u}$, and in which $b_{f}=4 k .^{8}$

\section{Equilibria}

We will analyze $G$ by characterizing a subset of its Bayes-perfect equilibria, where a buyer's belief assigns a probability distribution over the terms in a complex contract priced at $p$ : for every $p \in \Re .^{9}$ We denote the associated strategy combination and buyer beliefs as a $B P E$, describing a BPE in which the monopolist offers a simple [resp. complex] contract for sure as a simple [resp. complex] BPE. We will refer to the payoff vector in a BPE as a BPE outcome.

One might intuitively expect that the monopolist would be able to exert market power because she alone can draft contracts. However, this is not true of all BPEs. Roughly speaking, the monopolist may be deterred from charging higher prices for a complex contract in some BPEs because buyers believe that terms are then unfavorable. These BPEs arguably rely on buyers threatening to hold implausible beliefs about the terms in complex contracts which are not offered on the BPE path.

We explore the intuition that the monopolist's ideal BPE is played, using a refinement in the spirit of Fudenberg and Levine (1989). ${ }^{10}$ It is expositionally convenient to provide a formal definition of the refinement here, and to defer a more detailed explanation to a Remark at the end of Section 3.1 (following our main use of the refinement in Proposition 3.1 ).

For any game $G$, we define a class of perturbed games $G(e, \varepsilon)$ in which the monopolist is an $\varepsilon$-commitment type with probability $e>0$ and a normal type otherwise. Normal types have the same preferences as the monopolist in $G$; an $\varepsilon$-commitment type's play is

\footnotetext{
${ }^{8}$ The reasons why such nongeneric cases would complicate exposition will become clear below.

${ }^{9}$ The strategy combination in a Bayes-perfect equilibrium forms a Bayesian equilibrium after every move, given posterior beliefs which satisfy Bayes rule on the path, and the rules of the game elsewhere.

${ }^{10}$ While the details differ, Fudenberg and Levine motivate their approach as providing foundations for exactly this intuition (p.799).
} 
defined in terms of the supremum of monopoly payoffs across BPEs of $G$, say $\pi^{*}$. If $G$ has a BPE in which the monopolist earns $\pi^{*}-\varepsilon$ for some $\varepsilon>0$ then an $\varepsilon$-commitment type in $G(e, \varepsilon)$ plays her (possibly mixed) strategy in some such BPE; otherwise, the $\varepsilon$ commitment type in $G(e, \varepsilon)$ plays the monopolist's strategy in a BPE of $G$ where she earns $\pi^{*}$. Given this definition, we can characterize the BPEs of any perturbed game $G(e, \varepsilon)$, denoting the (mixed) strategy played by buyers and the normal type of the monopolist in a BPE of $G(e, \varepsilon)$ by $\sigma(e, \varepsilon)$. We say that beliefs plus a strategy combination $\sigma$ in $G$ are an $\varepsilon$-equilibrium of $G$ if they are a BPE of $G$ and if some sequence of perturbed games $\{G(e, \varepsilon)\}$ have BPEs with strategy combinations $\{\sigma(e, \varepsilon)\}$ which converge to $\sigma$ as $e \rightarrow 0$. We say that $\sigma$ is an equilibrium strategy combination of $G$ if it is the limit of some sequence of $\varepsilon$-equilibrium strategy combinations of $G$ as $\varepsilon$ converges to 0 . An outcome is the payoff vector at some equilibrium of $G$.

On one interpretation, our use of the refinement means that our model implicitly represents play in a repeated game. The monopolist then has market power because she is a long-run player. This interpretation is arguably appropriate when modelling fine print problems (cf. Bebchuk and Posner (2006)). However, we prefer to view the refinement as a way to preclude implausible beliefs, even if play is not repeated.

Efficiency

We will characterize equilibria of unregulated games which satisfy two assumptions on the benefits and costs of alternative terms. The first assumption states that buyers and sellers have conflicting interests over possible non-price terms:

\section{A1: Conflicting interests}

$$
b_{u}<b_{d}<b_{f} \text { and } c_{u}<c_{d}<c_{f}
$$

A1 seems natural in the context of our examples above of non-price terms.

The second assumption imposes conditions on how the social surplus from trade varies with the terms:

\section{A2: Efficient favorable terms}

$$
b_{f}-c_{f}>\max \left\{b_{d}-c_{d}, b_{u}-c_{u}\right\}>0 .
$$

We will refer to aggregate payoff (across the monopolist and buyers) as welfare. A2 implies that welfare is maximized when the monopolist trades favorable contracts with buyers who do not read.

A2 is, of course, empirically restrictive. We will return to the role that it plays in our analysis after Proposition 3.1 in Section 3.1.

We will henceforth normalize benefits and costs by setting $b_{u}=0$ (so $c_{u}$ could be negative).

We will refer to $\arg _{t \neq f} \max b_{t}-c_{t}$ as the second best terms, and a contract which only contains the second best terms as a second best contract. (If default terms are second best then the second best contract is simple.) We will use subscript 2 to denote the benefit and cost of second best terms. 


\section{Results}

In Section 3.1, we characterize equilibrium play in unregulated games. In Section 3.2, we define games in which the monopolist is regulated, characterize their equilibria, and compare outcomes with those in the unregulated game.

\subsection{Unregulated games}

Our first result provides grounds for considering regulation:

Lemma 1 Trade is inefficient in every BPE.

Proof Efficiency requires all trade to be in favorable contracts (cf. A2), and for no buyer to read. If the monopolist anticipated that a buyer would accept a favorable contract (without reading) then the monopolist could profitably deviate to offering an unfavorable contract at the same price. Consequently, every BPE is inefficient.

Drafters know the terms in complex contracts; whereas buyers must incur a socially wasteful cost to observe them directly. Lemma 1 asserts that this asymmetry of information must result in inefficient trade. We will explain this inefficiency in terms of commitment after Proposition 3.1 below.

Our next result describes necessary conditions for the monopolist to offer a favorable contract in a $\mathrm{BPE}$ :

\section{Lemma 2}

a The monopolist does not offer a (complex) default contract in any BPE.

b Any BPE in which the monopolist offers a favorable contract with positive probability has the following properties: the monopolist also offers an unfavorable contract at the same price as the favorable contract with positive probability; and buyers mix between accepting and reading a complex contract at that price, only accepting after reading favorable terms in the latter case.

In light of Lemma 2, we will henceforth refer to any BPEs in which the monopolist offers favorable contracts as semi-favorable.

We prove Lemma 2 in the Appendix. The argument for part a is that buyers must sometimes read, else the monopolist could profitably deviate to offering an unfavorable contract; and that buyers would only read if the monopolist sometimes offered a complex contract which was not favorable at the same price. Such a contract could not be default because the monopolist could then profitably deviate to offering a simple contract.

We will need some notation before stating our next result, which characterizes equilibria. We define $Y$ as $\sqrt{1-\frac{4 k}{b_{f}}}$ and $\widehat{p}$ as $\frac{2 k}{1-Y}$. It is easy to confirm that $\widehat{p}<b_{f}$ whenever $Y$ is well-defined.

\section{Proposition 3.1 (Unregulated games)}


Generic unregulated games have a unique equilibrium outcome, which is inefficient, and at which buyers expect to earn 0 . The monopolist mixes between offering an unfavorable and a favorable contract, each priced at $\widehat{p}$, if and only if $b_{f}>4 k$ and

$$
2 k>b_{2}-c_{2}+c_{f} \text { or } b_{f}>\frac{\left(b_{2}-c_{2}+c_{f}\right)^{2}}{b_{2}-c_{2}+c_{f}-k} .
$$

The monopolist otherwise offers a second best contract, priced at $b_{2}$.

We prove Proposition 3.1 in the Appendix. Lemma 1 immediately implies that every equilibrium must be inefficient. The remainder of the proof uses the following steps. We first demonstrate that a second best BPE in which the monopolist charges $b_{2}$ always exists, and that any other BPE is semi-favorable. We then prove that a semi-favorable BPE in which the monopolist charges $\widehat{p}$ exists if and only if the conditions in the premise hold: in other words, that the monopolist and buyers mutually discipline each other (cf. Lemma $2 a) . \quad b_{f}>4 k$ ensures that buyers sometimes read: the left-hand side should be read as the utility difference between accepting favorable and unfavorable contracts. The two conditions in (1) ensure that the monopolist cannot profitably deviate to offering a second best contract: the first condition bounds above the profit from such a contract $\left(b_{2}-c_{2}\right)$; the second condition bounds the BPE profit $\left(\widehat{p}-c_{f}\right)$ below because $\widehat{p}$ is an increasing function of $b_{f}$. We also note that $b_{f}>4 k$ and (1) are necessary for any semi-favorable BPE to exist, and that the monopolist then earns most (across BPEs) when she charges $\widehat{p}$ for a complex contract.

We end the proof by showing that the game has a unique equilibrium outcome. If $b_{f}>4 k$ and (1) then every semi-favorable BPE in which the monopolist charges $\hat{p}$ is an equilibrium; and no other BPE survives the refinement because the monopolist could profitably deviate to offering complex contracts priced just below $\widehat{p}$ in perturbed games. In particular, our refinement captures the intuition that semi-favorable BPEs at prices below $\widehat{p}$ rely on implausible buyer inferences. On the other hand, every BPE is second best if the conditions in the premise fail; so the unique outcome is second best.

The price charged in a semi-favorable equilibrium approaches $b_{f}$ as $k \rightarrow 0$ (by l'Hopital's rule); and the probability that terms are then favorable (viz. $(1+Y) / 2)$ approaches 1 as $k \rightarrow 0$. Furthermore, A2 implies that $b_{f}>b_{2}-c_{2}+c_{f}$; so $b_{f}>\max \left\{4 k, \frac{\left(b_{2}-c_{2}+c_{f}\right)^{2}}{b_{2}-c_{2}+c_{f}-k}\right\}$ when $k$ is small enough. Proposition 3.1 therefore implies that the monopolist must offer complex contracts, which are almost sure to be favorable, at a price close to $b_{f}$ when reading is almost costless. This property seems natural: for if reading were costless then the monopolist would offer a favorable contract, priced at $b_{f}$, in equilibrium.

This argument seems to underlie the claim that a monopolist would raise price rather than include unfavorable terms (cf. Rakoff (1983) and Baird (2000)): so trade in unregulated markets is efficient. This argument does not hold in our model, where reading is costly. Buyers must then inefficiently read in any semi-favorable equilibrium because the monopolist cannot commit to offering favorable contracts. Viewed in this light, the Baird-Rakoff argument implicitly supposes that a monopolist who charges more can commit to favorable terms. In the next subsection, we will explain how appropriately designed regulation eliminates the commitment problem and ensures efficiency. 
Proposition 3.1 is consistent with the evidence that terms are typically not unfavorable (cf. Mann and Siebeneicher (2008) and Marotta-Wurgler (2008)), and that buyers rarely read standard form contracts (cf. Bakos et al (2014)). The probability that complex contracts are favorable equals $\left(1+\sqrt{1-\frac{4 k}{b_{f}}}\right) / 2$; while buyers read a complex contract with probability $\left(c_{f}-c_{u}\right) /\left(\widehat{p}-c_{u}\right)$, where $\widehat{p}$ does not depend on the cost parameters. Hence, terms are usually favorable and buyers rarely read if $b_{f} / 4 k$ is large and $c_{f}$ is close to $c_{u}$.

Proposition 3.1 relies on A2. If trade in simple [resp. unfavorable] contracts maximized social surplus then the monopolist would offer a simple [resp. unfavorable] contract, priced at $b_{d}$ [resp. 0] in every BPE; so unregulated trade would be efficient.

\section{Remark (Refinement)}

Our refinement differs from that introduced by Fudenberg and Levine (1989) via our definition of an $\varepsilon$-commitment type. They consider perturbed games in which some player is a normal or a commitment type. The normal type has the same preferences as that player in the original game; the commitment type always chooses the player's stage Stackelberg pure strategy. Fudenberg and Levine select a BPE of the original game which is the limit of BPEs of perturbed games as the prior probability that the player is normal approaches $1 .^{11}$

In our model, the monopolist's Stackelberg strategy is to offer a favorable contract priced at $b_{f}$. The normal type would not pool with such a commitment type in any BPE of a perturbed game because buyers would have to accept, and the normal type could then profitably deviate to offering an unfavorable contract at price $b_{f}$. In other words, the ensuing refinement would have no power. Furthermore, introducing a commitment type who is sure to play the mixed strategy in the best complex BPE for the monopolist would not exclude second best BPEs because buyers could not improve on rejecting the commitment type's offer. Our refinement has power because an $\varepsilon$-commitment type offers a contract which buyers strictly prefer over rejecting.

Our refinement selects the BPE which maximizes welfare across BPEs because buyers expect to earn 0 in every BPE and because profit in a semi-favorable BPE increases with price, and exceeds profit in the second best BPE. The intuition is that a monopolist who charges a higher price is more likely to offer a favorable contract, and that buyers are consequently more likely to accept, thereby economizing on socially wasteful reading.

\subsection{Regulated markets}

Proposition 3.1 provides a possible reason why trade in standard form contracts might be regulated: that unregulated trade is inefficient because one-sided drafting creates an informational asymmetry. Specifically, if buyers observed contract terms (or reading were costless) then the monopolist would offer a favorable contract, and trade would be efficient. Inefficiency might therefore be avoided by mandating disclosure. Unfortunately, forcing sellers to display unfavorable terms does not translate into informing buyers, particularly in settings where fine print is an issue: that is, reading any disclosure is costly. Recent

\footnotetext{
${ }^{11}$ Mailath and Samuelson (2006) Ch.15 discuss Fudenberg and Levine's refinement; Ch.18 considers the consequences of alternative commitment types.
} 
evidence casts doubt on the efficacy of mandatory disclosure in such settings. ${ }^{12}$

The natural alternative to disclosure rules is regulation which renders some possible terms unenforceable. Despite the general principle that parties are free to negotiate contracts, courts, legislatures and regulators have sometimes over-ruled unfavorable terms in standard form contracts. Eisenberg (2009) traces court activism to the 1960s - particularly to §2-302 of the Uniform Commercial Code, which allowed courts to declare unconscionable terms unenforceable. This section was widely incorporated into state law, and was reformulated in $\S 208$ of Restatement (Second) of Contracts. ${ }^{13}$

In this subsection, we will use Proposition 3.1 to consider the welfare effects of regulations which mandate favorable terms or prohibit unfavorable terms, but do not address (upfront $=$ first clause) prices. $^{14}$ We will focus on the ex ante effects of regulation: that is, how regulations (or precedents) change the contracts which a monopolist offers. By contrast, fact-finding courts resolve ex post disputes: viz. conditional on an existing agreement. As we note below, this distinction only matters in our model when we consider regulations which prohibit unfavorable terms.

\subsubsection{Mandating regulation}

We start by considering the effects of regulations which mandate favorable terms but allow the monopolist to choose her price. We will refer to such a policy as mandating regulation, and the associated game as a mandating regulation game. The difference between these games and those presented in Section 2 is that the monopolist is constrained to offer a favorable contract. ${ }^{15}$ We will use the same solution concept (equilibrium) to characterize play under mandating regulation:

Lemma 3 If favorable terms are mandated then the monopolist charges $b_{f}$ and earns $b_{f}-c_{f}$, whereas buyers earn 0 . Trade is then efficient.

We can now use Proposition 3.1 and Lemma 3 to characterize the welfare effects of mandating favorable terms, again omitting the obvious proof:

Proposition 3.2 (Mandating regulation raises welfare) The outcome in mandating regulation games Pareto dominates the outcome in unregulated games.

Every equilibrium outcome in an unregulated market is inefficient because buyers must sometimes read for sellers to offer favorable contracts; and the monopolist must sometimes offer unfavorable contracts to ensure that buyers read. Mandating favorable terms directly disciplines the monopolist, allowing buyers to accept complex contracts without reading.

\footnotetext{
${ }^{12}$ Ben-Shahar and Schneider (2014) and Ayres and Schwartz (2014) discuss this evidence.

${ }^{13}$ In the UK, the 2014 Consumer Rights Act deems fine print terms unfair if they violate good faith requirements and are detrimental enough to buyers.

${ }^{14}$ Courts could find price unconscionable, but have been very reluctant to do so (cf. White and Summers (2010) §5-5 and 5-7). Paragraph 5.1 of the UK Consumer Rights Act exempts upfront prices from considerations of fairness.

${ }^{15} \mathrm{~A} 2$ implies that the same results apply to regulations which require that any complex contract be favorable, but allow the monopolist to offer simple contracts.
} 
While mandating regulation raises ex ante welfare, the monopoly is the sole beneficiary because buyers expect to earn 0 in both cases. This property is quite striking because the case for regulation in the related literature and court decisions has been that it protects buyers.

Proposition 3.2 explains why a regulator (with an ex ante perspective) would mandate favorable terms. The same policy is optimal for courts: A2 implies that replacing unfavorable or default terms in accepted contracts also raises welfare.

\subsubsection{Mitigating regulation}

We now turn to regulations which mitigate terms solely by prohibiting unfavorable contracts or making unfavorable terms unenforceable. We will refer to these as mitigating regulations. Regulations of this sort are instanced by restrictions on the use of mortgage prepayment penalties in the 1994 Home Ownership and Equity Protection Act.

Proposition 3.2 implies that regulators could achieve efficiency (in our model) by mandating favorable terms; but courts and regulators seem much more prone to prohibit unfavorable terms for at least two reasons. First, legal doctrine allows courts to replace unconscionable terms; whereas, mandating favorable terms may conflict with the doctrine that courts should intervene minimally. ${ }^{16}$ Second, identifying efficient terms may be unduly demanding for courts and regulators.

In this part, we consider the ex ante effects of regulations which prohibit unfavorable contracts. Specifically, we model a regulated market as a game in which the monopolist can offer a simple contract or a complex contract containing either favorable or default terms. Aside from this amendment, the game corresponds to that defined in Section 2. We call it a mitigating regulation game.

Despite the formal similarity between unregulated and mitigating regulation games, equilibrium play differs in one important respect. An unregulated monopolist would never offer default terms in a complex contract because she would earn more by offering an unfavorable contract were buyers to reject after reading default terms, and would otherwise earn more by offering a simple contract (cf. the proof of Lemma 2a). This argument does not apply if the monopolist is prohibited from offering unfavorable contracts. As the monopolist is better off with default terms when buyers accept without reading, there may then be equilibria in which she offers a complex contract with default terms (a default contract) and charges more than $b_{d}$.

This difference aside, we can exploit our analysis in Section 3.1 to characterize trade when the monopolist cannot offer unfavorable contracts. Specifically, in any semi-favorable $\mathrm{BPE}$, the monopolist must offer favorable contracts with probability $\psi$ and default contracts otherwise, charging $p=b_{d}+\frac{k}{1-\psi}$, where $\psi \in\left[\frac{1-Z}{2}, \frac{1+Z}{2}\right]$ and $Z \equiv \sqrt{1-\frac{4 k}{b_{f}-b_{d}}}$; while buyers must accept with probability $\frac{p-c_{f}}{p-c_{d}}$. As $p>c_{f}$ in any semi-favorable BPE, the only pertinent deviation for the monopolist is to offering a simple contract, which yields the same profit as in unregulated markets. Consequently, the arguments used to prove Proposition 3.1 apply to this subsection's model; and the conditions therein hold again, subject

\footnotetext{
${ }^{16}$ cf. Restatement (Second) of Contracts $\S 208$ Comment g and $\S 211(3)$.
} 
to replacing $b_{o} \equiv 0$ [resp. $c_{u}$ ] with $b_{d}>0$ [resp. $\left.c_{d}\right]$, and replacing unfavorable with default terms in any complex contract. (The probability that buyers read in a semi-favorable equilibrium now depends on $c_{d}$ plus the drafting cost.) Specifically:

Lemma 4 Generic mitigating regulation games have a unique outcome. Buyers expect to earn 0 at this outcome, which is inefficient. The monopolist mixes between offering a default and a favorable contract, each priced at $p^{+} \equiv b_{d}+\frac{2 k}{1-Z}$, if and only if $b_{f}-b_{d}>4 k$ and $2 k>c_{f}-c_{d}$ or $b_{f}-b_{d}>\frac{\left(c_{f}-c_{d}\right)^{2}}{c_{f}-c_{d}-k}$. The monopolist otherwise offers a simple contract, priced at $b_{d}$.

We omit the proof of Lemma 4 because it follows the same lines as the proof of Proposition 3.1. ${ }^{17}$

Mitigating regulation affects the existence of a semi-favorable equilibrium via buyers' incentives to read and via the monopolist's incentives to offer a default contract; and the welfare effects of mitigating regulation depend on whether a regulated and an unregulated monopolist each offer favorable contracts in equilibrium. Mitigating regulation would reduce profits and welfare if an unregulated monopolist offered an unfavorable contract for sure (so this contract would have to be second best) and $2 k<c_{f}-c_{d}$, as a regulated monopolist would then offer a simple contract.

Our main result in this part demonstrates that mitigating regulation can reduce welfare, via its effect on buyer incentives, when the unregulated game has a semi-favorable equilibrium:

\section{Proposition 3.3 (Mitigating regulation may reduce ex ante welfare) If}

$$
\max \left\{4 k, \frac{\left(b_{2}-c_{2}+c_{f}\right)^{2}}{b_{2}-c_{2}+c_{f}-k}\right\}<b_{f}<4 k+b_{d}
$$

then the outcome in unregulated games Pareto dominates the outcome in mitigating regulation games.

Proof The lower bound on $b_{f}$ in the premise implies that an unregulated monopolist offers a favorable contract with positive probability, earning more than $b_{d}-c_{d}$ (cf. Proposition 3.1). The upper bound on $b_{f}$ implies that $Z$ is undefined; so a regulated monopolist offers a simple contract, earning $b_{d}-c_{d}$ (cf. Lemma 4). Buyers expect to earn 0 in both regulated and unregulated markets, proving the result.

Unlike regulations which mandate favorable terms, mitigating regulations do not eliminate the monopolist's commitment problem: she now has an incentive to offer default terms in the hope that buyers will accept without reading. In particular, the monopolist only offers complex contracts in equilibrium if buyers have an incentive to read. For a fixed reading cost, this incentive is generated by the utility difference between the best and the worst terms that a complex contract might contain in equilibrium. Mitigating regulation

\footnotetext{
${ }^{17}$ We obtain the conditions for a semi-favorable equilibrium from $p^{+}-c_{f}>b_{d}-c_{d}$ : the condition which replaces $\widehat{p}-c_{f}>b_{2}-c_{2}$ in mitigating regulation games.
} 
reduces this utility difference. Consequently, the introduction of such regulations could force the monopolist to offer simple contracts. We exploit this effect in Proposition 3.3.

Proposition 3.3 states that mitigating regulation can reduce ex ante welfare. However, if default terms are second best then A2 implies that replacing unfavorable terms in accepted contracts with default or favorable terms always increases welfare. ${ }^{18}$ This difference between ex ante and ex post welfare effects restates why Proposition 3.3 seems so striking: regulations which raise welfare in court reduce welfare ex ante. The intuition is that the monopolist responds to regulations which prohibit unfavorable contracts by also no longer offering favorable contracts.

While mitigating regulation reduces buyers' incentives to read, it also reduces the monopolist's incentives to deviate from a putative semi-favorable equilibrium: on the one hand, the regulated monopolist earns more than her unregulated counterpart in putative semi-favorable equilibria (because $\widehat{p}<p^{+}$); on the other hand, mitigating regulation may reduce the profit earned by deviating to a second best contract. The monopolist would offer complex contracts, whether regulated or unregulated, if the conditions in Proposition 3.3 were replaced by $b_{f}>\max \left\{4 k, \frac{\left(c_{f}-c_{d}\right)^{2}}{c_{f}-c_{d}-k}\right\}+b_{d}$. The outcome in the mitigating regulation game then Pareto dominates that in an unregulated game: for $Y<Z$ if both are welldefined, which implies that $\widehat{p}<p^{+}$; so mitigating regulation then increases profit without affecting buyer payoffs.

It is instructive to consider a particular policy application of our results. Engel and McCoy (2002) argue that subprime lenders had monopoly power, which they exploited to include unfavorable terms in complex mortgage contracts. Engel and McCoy argue in favor of mitigating regulations, such as waiving legal redress. Our results suggest that this regulation may reduce welfare by driving all complex contracts, including favorable ones, from the market. ${ }^{19}$ In the next section, we will argue that the deleterious effects of mitigating regulation may be reinforced if some buyers are naively optimistic. This supposition seems appropriate in the market for subprime mortgages as Bucks and Pence (2008) show that mortgage borrowers held systematically optimistic beliefs about the terms in their adjustable rate mortgages. ${ }^{20}$

\section{Naive buyers}

Thus far, we have focused on play when buyers are sophisticated. Court decisions and the legal literature suggest that standard form contracts should be regulated in order to protect naive buyers. ${ }^{21}$ In this section, we follow the recent literature by considering the effects of regulation when some buyers naively believe that all complex contracts are favorable. Specifically, we suppose that the monopolist knows the proportion of naive

\footnotetext{
${ }^{18}$ By contrast, mandating favorable terms raises welfare both ex ante and ex post.

${ }^{19} \mathrm{~J}$. Stevens articulated this justification for Chapter 13 rules when concurring in Nobleman v. American Savings Bank 508 U.S. 324 (1993).

${ }^{20}$ Armstrong and Vickers (2012) argue that UK consumers have been (on average) naively optimistic about overdraft charges.

${ }^{21}$ Restatement (Second) of Contracts $\S 211(\mathrm{c})$ states that a clause is unenforceable if a buyer would not have traded had he known its contents.
} 
buyers (henceforth $n$ ) but cannot identify (and therefore directly target) them. In light of the heterogeneity of buyers, we further amend the model by supposing that the monopolist can offer a menu of contracts.

Naive buyers hold beliefs which are sometimes false; so we model them as dummy players. Specifically, we compute naive buyers' perceived utility for any menu of contracts, and assume that they each choose best responses, given their beliefs. In particular, naive buyers never read, and only accept the cheapest simple or the cheapest complex contract on offer. If the cheapest simple and complex contracts are respectively priced at $p_{s}$ and $p_{c}$ then naively optimistic buyers only accept the former if $p_{s} \leq b_{d}+\min \left\{p_{c}-b_{f}, 0\right\}$, and only accept the latter if $p_{c} \leq b_{f}+\min \left\{p_{s}-b_{d}, 0\right\}$.

We refer to the other buyers as sophisticated. These buyers select one of the contracts on offer, which they then accept, reject or read. If the monopolist offers more than one contract then sophisticated buyers' beliefs about the terms in each complex contract on offer may depend on the entire menu, rather than just on the price of that complex contract. (We will exploit this feature below.)

Naive buyers value a complex contract at least as highly as sophisticated buyers. Consequently, naive and sophisticated buyers cannot respectively accept a simple and a complex contract in any BPE. Furthermore, there cannot be a BPE in which simple contracts are traded at different prices, as no buyer would accept the more expensive of two contracts; and there cannot be a BPE in which simple contracts alone are traded, as the monopolist could profitably deviate to offering an unfavorable contract which attracts naive buyers. Finally, arguments used in the proof of Proposition 3.1 imply that sophisticated buyers who accept a favorable contract must again mix between accepting and reading it: which is again only possible in a $\mathrm{BPE}$ if $b_{f} \geq 4 k$.

For current purposes, we need to use the weaker refinement of an $\varepsilon$-equilibrium, which we introduced in Section 2, focusing of course on play when $\varepsilon$ is small enough. We use an online appendix to explain why unregulated games lack an equilibrium, as well as other unproven claims in this section. ${ }^{22}$

If all buyers are naive then an unregulated monopolist offers an unfavorable contract, priced at $b_{f}$, in every BPE, and therefore every $\varepsilon$-equilibrium. The monopolist offers a favorable contract, priced at $b_{f}$ under mandating regulation, and a default contract priced at $b_{f}$ under mitigating regulation. Hence, both regulations benefit the naive buyers at the expense of the monopolist. Mandating regulation always raises welfare, whereas mitigating regulation raises welfare if and only if default terms are second best.

The analysis of games in which $n \in(0,1)$ is more subtle because the monopolist can use her menu to screen buyers. We focus on games in which few enough buyers are naive, exploring when and how the naive buyers may be protected by their sophisticated counterparts in unregulated markets, and how regulation affects such protection.

We will adopt the following assumption - which imposes nontrivial restrictions on the model's parameters - throughout this section:

\section{A3}

a Default terms are second best;

b $2\left(b_{d}-c_{d}+c_{f}\right)<4 k<b_{f}<4 k+b_{d}<5 k$;

\footnotetext{
${ }^{22}$ The appendix is available at www.nottingham.ac.uk/economics/documents/eeronlineapp.pdf
} 


$$
\begin{aligned}
& \text { c } n b_{f}<2 k-(1-n)\left(b_{d}-c_{d}+c_{f}\right) ; \\
& \text { d } \varepsilon<\min \left\{n\left(c_{f}-c_{u}\right), 2 n \widehat{p}, \widehat{p}-n b_{f}-(1-n)\left(b_{d}-c_{d}+c_{f}\right)\right\} .
\end{aligned}
$$

As $b_{f}>4 k$, A3c can only also be satisfied if $n$ is small enough; $b_{f}>4 k$ and A3c also imply that the right-hand side of the inequality in A3d is positive. The first two inequalities in A3b imply that the conditions in the premise of Proposition 3.1 are satisfied: the equilibrium of an unregulated game with no naive buyers is semi-favorable.

A3 implies that an unregulated monopolist offers complex contracts priced at $p$ and at $q$ (where $0<q<p<\widehat{p}$ ), earning less than

$$
\pi^{*} \equiv \widehat{p}-n c_{u}-(1-n) c_{f},
$$

the supremum across BPEs of the monopolist's payoff, in any $\varepsilon$-equilibrium. The cheaper contract is unfavorable, and is accepted by naive buyers. The other contract is unfavorable with probability $k / p$, and is otherwise favorable, and is only accepted by sophisticated buyers. Naive buyers' payoff is negative because they pay a positive price for an unfavorable contract. (See Claim in the online appendix.) The predicted separation is consistent with Schwarcz's (2011) evidence of segmentation in the market for home insurance.

While naive and sophisticated buyers accept different contracts, sophisticated buyers protect naive buyers in these $\varepsilon$-equilibria. Specifically, naive buyers would be prepared to pay up to $b_{f}$ for complex contracts; but the monopolist charges them less because she also wants to offer complex contracts to sophisticated buyers, who would reject complex contracts priced above $\widehat{p}$. The monopolist must therefore charge naive buyers less than she charges sophisticated buyers. Sophisticated buyers also protect (few enough) naive buyers in Schwartz and Wilde (1983) and the ensuing literature. However, the effect occurs there because sellers cannot offer a menu of contracts which screens buyers. ${ }^{23}$

We now turn to the effect of regulation on markets which contain naive buyers. Under mandating regulation, the monopolist offers a favorable contract, priced at $b_{f}$, resulting in efficient trade. A3 implies that the regulated monopolist's profit exceeds $\pi^{*}$ : the upper bound on her profits when unregulated. Naive buyers also benefit from mandating regulation because they then earn 0. These observations extend Proposition 3.2 (no naive buyers).

Now suppose that the monopolist is prohibited from offering unfavorable contracts. The monopolist then offers a simple contract priced at $b_{d}$ and a default contract priced at $b_{f}$, which sophisticated and naive buyers respectively accept in every BPE: for $b_{f}<4 k+b_{d}$ (in A3b) implies that $Z$ is undefined, so sophisticated buyers cannot accept a complex contract.

Naive buyers earn $b_{d}-b_{f}$ in every $\varepsilon$-equilibrium of the mitigating regulation game, and earn more than $-\widehat{p}$ in every $\varepsilon$-equilibrium of the unregulated game because $q<\widehat{p}$. A3b implies that $b_{d}<k$, and therefore that $b_{d}-b_{f}<-\widehat{p}$; so mitigating regulation harms naive buyers. In particular, naive buyers pay a higher price for a complex contract with better terms in a regulated market. A3 implies that the former effect dominates: few enough naive buyers are harmed because sophisticated buyers no longer protect them under mitigating regulation. By contrast, mitigating regulation benefits buyers if they are all naive.

\footnotetext{
${ }^{23}$ See, in particular, Armstrong and Vickers (2012).
} 
Now consider the menu which a regulated monopolist offers in equilibrium. Sophisticated [resp. naive] buyers would also have accepted a simple [resp. default] contract priced at $b_{d}\left[\right.$ resp. $\left.b_{f}\right]$ in an unregulated market; so mitigating regulation must harm the monopolist. Finally, sophisticated buyers expect to earn about 0 in every $\varepsilon$-equilibrium, irrespective of the legal regime. Consequently, mitigating regulation must reduce welfare, even though default terms are second best (so this regulation would raise welfare when all buyers are naive).

We summarize these arguments in:

\section{Proposition 4.1 (The effect of regulation with naive buyers) If $A 3$ then}

a Trade under mandating regulation is efficient. Mandating regulation benefits the monopolist and naive buyers.

b Mitigating regulation harms naive buyers and the monopolist, and reduces welfare.

\section{Conclusion}

We have analyzed the effect of regulations in a simple model of trade between a monopolist and sophisticated buyers. Mandating favorable terms unsurprisingly induces efficient trade. However, identifying efficient terms may be more difficult for courts or regulators than identifying terms which are manifestly inefficient. We show that an unregulated monopolist may offer a contract containing the latter terms; so mitigating regulation may affect trade. Our main results demonstrate that this effect may reduce welfare.

We have extended our main model to incorporate naive buyers, demonstrating that our results carry over to such settings. Indeed, the presence of naive buyers could reinforce the (potentially) deleterious effects of mitigating regulation by removing the protection that sophisticated buyers provide in an unregulated monopoly. 


\section{REFERENCES}

Armstrong, M. (2015), "Search and Ripoff Externalities" Review of Industrial Organization 47, 273-302.

Armstrong, M. and D. Sappington (2007), "Recent Developments in the Theory of Regulation" in M. Armstrong and R. Porter Handbook of Industrial Organization Vol 3 North Holland, Amsterdam.

Armstrong, M. and J. Vickers (2012), "Consumer Protection and Contingent Charges" Journal of Economic Literature 50, 477-493.

Armstrong, M., J. Vickers and J. Zhou (2009), "Consumer Protection and the Incentive to Become Informed" Journal of the European Economic Association 7, 399-410.

Avenhaus, R. and M. Canty (2009), "Inspection Games" in R. Meyers ed. Encyclopedia of Complexity and Systems Science Springer, New York.

Avenhaus, R., B. von Stengel and S. Zamir (2002), "Inspection Games" in R. Aumann and S. Hart eds. Handbook of Game Theory Vol III North Holland, Amsterdam.

Ayres, I. and A. Schwartz (2014), "The No Reading Problem in Consumer Contract Law" Stanford Law Review 66, 545-609.

Baird, D. (2000), "Commercial Norms and the Art of the Small Con" Michigan Law Review 98, 2716-2726.

Bakos, Y., F. Marotta-Wurgler and D. Trossen (2014), "Does Anyone Read the Fine Print?" Journal of Legal Studies 43, 1-36.

Beale, H. (2007), "Exclusion and Limitation Clauses in Business Contracts: Transparency" in A. Burrows and E. Peel eds. Contract Terms Oxford University Press, Oxford.

Beales, H., R. Craswell and S. Salop (1981), "The Efficient Regulation of Consumer Information" Journal of Law and Economics 24, 491-539.

Bebchuk, L. and R. Posner (2006), "One-sided Contracts in Competitive Consumer Markets" Michigan Law Review 104, 827-835.

Ben-Shahar, O. and C. Schneider (2014), More Than You Wanted to Know Princeton University Press, Princeton.

Bucks, B. and K. Pence (2008), "Do Borrowers Know Their Mortgage Terms?" Journal of Urban Economics 64, 218-233.

Che, Y-K and A. Choi (2009), "Shrink-Wraps: Who Should Bear the Cost of Communicating Mass-market Contract Terms?", mimeo.

D'Agostino, E. and D. Seidmann (2016), "Protecting Buyers from Fine Print: Online Appendix", available at www.nottingham.ac.uk/economics/documents/eeronlineapp.pdf.

Eisenberg, M. (2009), "The Role of Fault in Contract Law" Michigan Law Review 47, 1413-1430.

Eliaz, K. and R. Spiegler (2006), "Contracting with Diversely Naive Agents" Review of Economic Studies 73, 689-714.

Eliaz, K. and R. Spiegler (2008), "Consumer Optimism and Price Discrimination" Theoretical Economics 3, 459-497.

Engel, K. and P. McCoy (2002), "A Tale of Three Markets: The Law and Economics of Predatory Lending" Texas Law Review 80, 1259-1381.

Fudenberg, D. and D. Levine (1989), "Reputation and Equilibrium Selection in Games with a Patient Player" Econometrica 57, 759-778. 
Gabaix, X. and D. Laibson (2006), "Shrouded Attributes, Consumer Myopia and Information Suppression in Competitive Markets" Quarterly Journal of Economics 121, 505540.

Grubb, M. (2015a), "Consumer Inattention and Bill-Shock Regulation" Review of Economic Studies 82, 219-257.

Grubb, M. (2015b), "Overconfident Consumers in the Marketplace" Journal of Economic Perspectives 29, 9-36.

Heidhues, P. and B. Koszegi (2010), "Exploiting Naïvete about Self-Control in the Credit Market" American Economic Review 100, 2279-2303.

Heidhues, P., B. Koszegi and T. Murooka (2014), "Inferior Products and Profitable Deception", mimeo.

Hermalin, B., A. Katz and R. Craswell (2007), "Contract Law" in A. Polinsky and S. Shavell eds. Handbook of Law and Economics Vol 1 Elsevier, New York.

Huck, S. and J. Zhou (2011), "Consumer Behavioral Biases in Competition: A Survey", Office of Fair Trading.

Katz, A. (1990), "Your Terms or Mine? The Duty to Read the Fine Print in Contracts" Rand Journal of Economics 21, 518-537.

Kessler, F. (1943), "Contracts of Adhesion - Some Thoughts about Freedom of Contract" Columbia Law Review 43, 629-642.

Korobkin, R. (2003), "Bounded Rationality and Unconscionability: A Behavioral Approach to Policing Form Contracts" University of Chicago Law Review 70, 1203-1295.

Koszegi, B. (2014), "Behavioral Contract Theory" Journal of Economic Literature 52, 1075-1118.

Mailath, G. and L. Samuelson (2006), Repeated Games and Reputations: Long-run Relationships Oxford University Press, Oxford.

Mann, R. and T. Siebeneicher (2008), "Just One Click: The Reality of Internet Retail Contracting" Columbia Law Review 108, 984-1012.

Marotta-Wurgler, F. (2008), "Competition and the Quality of Standard Form Contracts" Journal of Empirical Legal Studies 5, 447-475..

Rakoff, T. (1983), "Contracts of Adhesion: An Essay in Reconstruction" Harvard Law Review 96, 1173-1284.

Rasmusen, E. (2001), "Explaining Incomplete Contracts as the Result of Reading Costs" Advances in Economic Analysis and Policy 1 (1), Article 2.

Schwarcz, D. (2011), "Reevaluating Standardized Insurance Policies" University of Chicago Law Review 78, 1263-1348.

Schwartz, A. and L. Wilde (1983), "Imperfect Information in Markets for Contract Terms" Virginia Law Review 69, 1394-1466.

Spiegler, R. (2011), Bounded Rationality and Industrial Organization Oxford University Press, Oxford.

White, J. and R. Summers (2010), Uniform Commercial Code 6th ed. West, St Paul MN.

Zamir, E. (2014), "Contract Law and Theory" University of Chicago Law Review 81, 2077-2123. 


\section{APPENDIX (PROOFS)}

\section{Lemma 2}

a The monopolist does not offer a (complex) default contract in any BPE.

b Any BPE in which the monopolist offers a favorable contract with positive probability has the following properties: the monopolist also offers an unfavorable contract at the same price as the favorable contract with positive probability; and buyers mix between accepting and reading a complex contract at that price, only accepting after reading favorable terms in the latter case.

\section{Proof}

a Suppose, per contra, that the monopolist offered $\{p, d\}$. There are two cases to consider. If a buyer would reject after reading $\{p, d\}$ then he would also reject after reading $\{p, u\}$, so the monopolist would be indifferent between the two contracts in the event that the buyer read. As the buyer accepts with positive probability, the monopolist would prefer to offer $\{p, u\}$. Now suppose that a buyer would accept with positive probability after reading $\{p, d\}$. The price could then not exceed $b_{d}$, in which case the monopolist could economize on the drafting cost by offering a simple contract, priced at $p$. In sum, the monopolist cannot offer a default contract in any BPE.

b A2 implies that the monopolist can earn positive profits by offering a second best contract. Consequently, buyers must accept any complex contract that the monopolist offers with positive probability (possibly after reading) in any BPE.

Suppose that the monopolist offers a favorable contract in a BPE. If buyers never read then the monopolist could profitably deviate to offering an unfavorable contract at the same price. A buyer who reads must accept a favorable contract and reject a contract which contains some other terms, else he could profitably deviate to not reading. Finally, buyers must sometimes accept without reading: for A2 would otherwise imply that the monopolist would offer a favorable contract for sure, in which case buyers could profitably deviate to not reading, as they could infer terms from the price. Hence, a monopolist who offers a favorable contract, priced at $p$, must offer another complex contract priced at $p$ with positive probability. Part a above implies that this contract must be unfavorable.

\section{Proposition 3.1 (Unregulated games)}

Generic unregulated games have a unique equilibrium outcome, which is inefficient, and at which buyers expect to earn 0 . The monopolist mixes between offering an unfavorable and a favorable contract, each priced at $\widehat{p}$, if and only if $b_{f}>4 k$ and

$$
2 k>b_{2}-c_{2}+c_{f} \text { or } b_{f}>\frac{\left(b_{2}-c_{2}+c_{f}\right)^{2}}{b_{2}-c_{2}+c_{f}-k} .
$$

The monopolist otherwise offers a second best contract, priced at $b_{2}$.

Proof Lemma 1 immediately implies that every equilibrium must be inefficient. We will prove the other claims in the Proposition using the following steps. We start by proving 
existence of and characterizing second best BPEs, arguing that every BPE is either second best or semi-favorable. We then prove existence of a semi-favorable BPE in which the monopolist charges $\widehat{p}$ if and only if the conditions in the premise hold. We end the proof by applying our refinement to the set of BPEs.

\section{Step 1 The second best BPE outcome}

The following strategy combination and beliefs form a BPE.

The monopolist offers a second best contract, priced at $b_{2}$. Buyers accept a simple [resp. complex] contract priced no higher than $b_{d}$ [resp. 0], believing that any complex contract is unfavorable. After reading a complex contract which contains terms $t$ and is priced at $p$, buyers accept if and only if $b_{t} \geq p$.

A2 implies that the monopolist cannot profitably deviate to offering either any other complex contract or any simple contract at another price. Buyers' beliefs are sequentially rational.

Lemma 2 implies that the monopolist must offer the unfavorable contract for sure in any complex BPE which is not semi-favorable. The monopolist must offer the second best contract, priced at $b_{2}$, in any BPE which is not semi-favorable, as she could otherwise profitably deviate to offering that contract.

Buyer beliefs about the terms in complex contracts may differ across second best BPEs; but generic games (where $b_{d}-c_{d} \neq-c_{u}$ ) have a unique second best BPE outcome, in which buyers earn 0 .

Step 2 Semi-favorable BPE outcomes

Suppose that $b_{f}>4 k$ and (1). We claim that the following strategy combination and beliefs form a semi-favorable BPE:

The monopolist offers $\{\widehat{p}, f\}$ with probability $\frac{1+Y}{2}$, and otherwise offers $\{\widehat{p}, u\}$. After reading contract $\{p, t\}$, buyers accept if and only if $b_{t} \geq p$. Buyers believe that a complex contract priced at $\widehat{p}$ is favorable with probability $\frac{1+Y}{2}$, and is otherwise unfavorable. They accept a complex contract priced at $\widehat{p}$ with probability $\frac{\widehat{p}-c_{f}}{\widehat{p}-c_{u}}$ and read otherwise, accepting if and only if the terms are favorable. Buyers believe that any complex contract priced at $p \neq \widehat{p}$ is unfavorable. They accept such a contract without reading if $p \leq 0$, and otherwise reject. Buyers accept a simple contract if and only if its price does not exceed $b_{d}$.

$b_{f}>4 k$ implies that $Y$ and $\widehat{p}$ are well-defined. Note, for future reference, that $\frac{1-Y}{2}=\frac{k}{\hat{p}}$.

Buyer beliefs are sequentially rational. Buyers expect to earn $\frac{1+Y}{2} b_{f}-\widehat{p}$ if they accept a complex contract, priced at $\widehat{p}$, and expect to earn $\frac{1+Y}{2}\left(b_{f}-\widehat{p}\right)-k$ if they read that contract; so the definition of $\widehat{p}$ implies that they are indifferent. It is easy to confirm that their expected payoff is 0 . (1) implies that $\widehat{p}>c_{f}$; so A1 implies that $\frac{\widehat{p}-c_{f}}{\widehat{p}-c_{u}} \in(0,1)$. (1) also implies that $\widehat{p}>b_{d}$ : so buyers cannot profitably deviate to accepting a default contract, priced at $\widehat{p}$ after reading. Conditional on their beliefs, buyers can therefore not profitably deviate. 
Given buyer strategies, the monopolist earns $\widehat{p}-c_{f}$ if she offers either $\{\widehat{p}, f\}$ or $\{\widehat{p}, u\}$, and cannot profitably deviate to offering $\{\widehat{p}, d\}$. By definition of $Y, \frac{1+Y}{2} \in(0,1)$.

As $\widehat{p}>c_{f}$, the monopolist cannot profitably deviate to offering a contract which buyers would reject.

Buyers accept complex contracts priced at $p \neq \widehat{p}$ if and only if $p \leq 0$; so the monopolist would earn no more than $-c_{u}$ by offering a complex contract which buyers accept. Furthermore, the monopolist would earn no more than $b_{d}-c_{d}$ by offering a simple contract. Consequently, the monopolist cannot profitably deviate to offering an accepted contract if and only if

$$
\widehat{p}-c_{f}>b_{2}-c_{2} .
$$

Substituting for $\widehat{p}$ and rearranging: (1) and (2) are equivalent.

In sum, the monopolist cannot profitably deviate; so the specified strategy combination and beliefs form a BPE.

Inspection of the arguments above reveals that, if (2) holds, then there are also semifavorable BPEs in which the monopolist offers $\{p, u\}$ with probability $k / p$ and $\{p, f\}$ otherwise, for some $p \in\left(c_{f}, \widehat{p}\right)$. The monopolist earns $p-c_{f}$ in any such BPE. Consequently, such BPEs only exist if there is a semi-favorable BPE in which the monopolist charges $\widehat{p}$, and the monopolist earns most in the BPE where she charges $\widehat{p}$.

We now argue that $b_{f}>4 k$ and (1) are necessary for a semi-favorable BPE to exist. Lemma 2 implies that, in any semi-favorable BPE: the monopolist offers $\{p, f\}$ with probability (say) $\mu$ and $\{p, u\}$ otherwise, and that buyers mix between accepting and reading a complex contract priced at $p$. Buyers can only be indifferent between accepting and reading if $p=\frac{k}{1-\mu}$, in which case they prefer not to reject if and only if $b_{f} \mu^{2}-b_{f} \mu+k \leq 0$. This condition is only consistent with $\mu \in(0,1)$ if $b_{f}>4 k$. Next, observe that the monopolist earns $p-c_{f}$ in any semi-favorable BPE where she charges $p$. As $p=\frac{k}{1-\mu}$ and buyers cannot prefer to reject in any semi-favorable BPE, the monopolist cannot earn more than $\widehat{p}-c_{f}$ in any such BPE. The monopolist would earn up to $b_{2}-c_{2}$ by offering the second best contract in any BPE. As (1) and (2) are equivalent, the monopolist could profitably deviate to offering a second best contract if (1) failed.

Step 3 Selecting equilibrium outcomes

We now consider which BPEs satisfy our refinement.

Suppose, first, that $b_{f}>4 k$ and (1) holds. The monopolist is then better off in the BPEs where she charges $\widehat{p}$ than in any other semi-favorable BPE, and than in the second best BPEs (by (2)). This allows us to define the $\varepsilon$-commitment type (for $\varepsilon$ small enough) in perturbed games $G(e, \varepsilon)$ as a monopolist who offers $\left\{\widehat{p}^{\varepsilon}, u\right\}$ with probability $k / \widehat{p}^{\varepsilon}$ and $\left\{\widehat{p}^{\varepsilon}, f\right\}$ otherwise: where $\widehat{p}^{\varepsilon} \equiv \widehat{p}-\varepsilon$ and $0<\varepsilon<\widehat{p}-c_{f}-\left(b_{2}-c_{2}\right)$ : so the monopolist charges $\widehat{p}^{\varepsilon}$ in a semi-favorable BPE of the original game, $G$. We first demonstrate that $G(e, \varepsilon)$ has no BPE in which the monopolist offers a second best contract:

Buyers and the (normal type of) monopolist respectively earn 0 and $b_{2}-c_{2}$ in any second best BPE; so buyers would not reject a complex contract priced at $\widehat{p}^{\varepsilon}<\widehat{p}$. Accordingly, suppose that the normal type deviated to offering $\left\{\widehat{p}^{\varepsilon}, f\right\}$. Buyers would accept, possibly after reading, and the monopolist would earn $\widehat{p}^{\varepsilon}-c_{f}$. This deviation is profitable because $\widehat{p}^{\varepsilon}-c_{f}>b_{2}-c_{2}$. Hence, no BPE of $G(e, \varepsilon)$ prescribes the normal type to offer a second best contract when $\varepsilon$ is small enough; so $G$ does not have a second best equilibrium. 
We now argue that $G$ has a semi-favorable equilibrium. Consider a strategy combination in $G(e, \varepsilon)$ where the normal and the $\varepsilon$-commitment type pool: both offering contracts priced at $\widehat{p}^{\varepsilon}$. The normal type cannot profitably deviate to offering either a simple contract or a complex contract priced at $p \neq \widehat{p}^{\varepsilon}$ if buyers believe that such a contract is unfavorable. Arguments used in Step 2 above also imply that buyers cannot profitably deviate. Consequently, $G(e, \varepsilon)$ has a BPE in which the monopolist mixes between offering $\left\{\widehat{p}^{\varepsilon}, f\right\}$ and $\left\{\widehat{p}^{\varepsilon}, u\right\}$. Taking limits as $e$ and $\varepsilon$ each approach 0 (and therefore as $\widehat{p}^{\varepsilon} \rightarrow \widehat{p}$ ), G has a semi-favorable equilibrium in which the monopolist charges $\widehat{p}$.

If $b_{f}<4 k$ or (1) fails then every BPE is second best. Accordingly, the monopolist's $\varepsilon$-commitment type in $G(e, \varepsilon)$ offers a second best contract, priced at $b_{2}$. By construction, the $\varepsilon$-commitment type offers the same contract in $G(e, \varepsilon)$ as the monopolist offers in the second best BPE in $G$. Buyers may then infer (in $G(e, \varepsilon)$ ) that any complex contract that the monopolist offers is unfavorable. The monopolist then has no profitable deviation in $G(e, \varepsilon)$ from offering a second best contract priced at $b_{2}$; and buyers cannot profitably deviate (cf. Step 1). Consequently, this is the only outcome in $G$. 